\section{LA OBRA DE EL GRECO EN EL MERCADO DE ARTE}

\author{
Amelia López-Yarto Elizalde \\ Consejo Superior de Investigaciones Científicas \\ amelialy@hotmail.es
}

\section{EL GRECO'S WORK IN THE ART MARKET}

Cómo citar este artículo/Citation: López-Yarto Elizalde, A. (2015). "La obra de El Greco en el mercado de arte". Arbor, 191 (776): a278. doi: http://dx.doi.org/10.3989/ arbor.2015.776n6005
Copyright: (c) 2015 CSIC. Este es un artículo de acceso abierto distribuido bajo los términos de la licencia Creative Commons Attribution-Non Commercial (by-nc) Spain 3.0.
RESUMEN: La atracción que ejerció El Greco en los coleccionistas se inició mucho después que la de otros pintores españoles. Aunque a lo largo del siglo XIX ya salieron de España cuadros muy importantes, será en los últimos veinte años del siglo cuando los cuadros de devoción fueron más apreciados. Las publicaciones de Cossío y la exposición celebrada en el Museo del Prado en 1902 hicieron subir mucho la cotización del pintor que irá en aumento a lo largo del siglo XX. En este artículo se ha estudiado la presencia de El Greco en las salas de subastas a través de la sección Mercado de Arte de la revista Archivo Español de Arte que nos ha llevado a varias conclusiones.

PALABRAS CLAVE: El Greco; subastas de arte; coleccionistas; valoración de la pintura de El Greco; procedencia de los cuadros.
ABSTRACT: El Greco started to attract collectors' attention much later than other Spanish painters. Although some very important paintings left Spain during the nineteenth century, it was in the last twenty years of the century when devotional paintings came to be more appreciated. Cossio's publications and the exhibition at the Prado Museum in 1902 drove up the price of the painter's works, which continued to rise throughout the twentieth century. This article has studied in the presence of El Greco's works at auction houses through the "art market" section of the Spanish magazine Archivo Español de Arte and has led us to several conclusions.

KEYWORDS: El Greco; auctions of art; collectors; valuation of El Greco's paintings; origin of works. 
Durante muchos siglos, los pintores trabajaban mediante contrato, realizando las obras que les encargaban directamente los clientes. Es cierto que existía la venta por subasta de todo tipo de mercancías desde tiempos remotos, pero los objetos de arte siempre se consideraron objetos de lujo cuya compra debía de seguir otros derroteros. Cuando empieza a haber coleccionistas de Arte, ya no buscan solo la obra reciente sino, también, obras antiguas a las que era más difícil tener acceso. Por eso surgen las casas de subastas, que ponen en contacto a vendedor y comprador. La primera que abrió sus puertas fue la Casa Spink, de Londres, en 1666. Como el negocio seguía creciendo, en el siglo XVIII se fundaron nuevas casas de subastas como Dorotheum, fundada por el Emperador José I en 1707 en Viena, Sotheby's (11 de marzo de 1744), Christie's (5 de diciembre de 1766), Bloomsbury (1759), Bonhams (1793), Philips (1796) en Londres. Las tres primeras continúan activas, aunque las más prestigiosas son las dos primeras inglesas. Ambas abrieron casa en Nueva York en la década de los 50 del siglo XX y se expandieron por toda Europa (Génova, Milán, París y Zurich la primera; Amsterdam, Ginebra, Milán y París la segunda) y por Oriente, cercano y lejano, cuando los nuevos capitales orientales se iniciaron en el gusto por el coleccionismo. Sotheby's (en adelante S.) tiene casas en Beijing, Hong Kong y Doha. Mientras que Christie's (en adelante Ch.) tiene en Dubai, Hong Kong, Mumbai y Shangai. Además ambas tienen numerosos colaboradores y representantes en muchos otros lugares. Londres se convirtió en la capital europea del mercado de Arte. Por supuesto hay otras Casas de subastas con prestigio en París (Hôtel Drouot, 1 de junio de 1852), Alemania, Suiza y Austria, como no, pero ninguna ha crecido tanto como las dos citadas (Vico Belmonte, 2008).

El comercio de Arte mediante subastas llegó a España más tarde, es bastante más reducido y salen pocas obras de primera calidad. La primera casa que se abrió en Madrid fue Durán en 1969, que más tarde se escindió en dos: Durán y Fernando Durán. El número de salas siguió creciendo, llegando a haber 15 en 1983: 5 en Madrid, 8 en Barcelona, una en Sevilla y una en Olot. Desde esta fecha la suerte de las salas ha sido muy diversa. Incluso en algún momento se abrieron nuevas, pero la mayoría tuvieron una trayectoria muy corta. Las más grandes han conseguido sobrevivir, pero las pequeñas, como Fortuny, tuvieron que cerrar. En estos momentos las que tienen más ventas son Durán, Fernando Durán, Ansorena (1974) y Sala Retiro (fundada en 1992 por Caja Madrid, hoy Bankia), todas en Madrid (Ruiz López, 2007). Finalmente, hay que te- ner en cuenta la importancia que están empezando a tener las subastas on line en Internet. El Ministerio de Economía y Hacienda publicó en 1992 la ley 37/1992 que, en un de sus artículos, establece una regulación del mercado del Arte (Bailén Vega, 2007).

Desde el momento en que surgen las Casas de subastas, se empiezan a imprimir catálogos con la lista de los objetos que se ofrecían. Los catálogos del siglo XIX, que son los más antiguos a los que he tenido acceso, aportaban muy pocos datos: nombre del artista si lo sabían, título, medidas y precio de salida. Pero desde los años 50 del siglo XX hasta ahora, han ido mejorando no solo en el papel de impresión, sino también en los datos técnicos, históricos y artísticos que aportan los especialistas en muchas de las fichas y están ilustrados con magníficas reproducciones fotográficas. Así, la revisión de los catálogos es una inestimable ayuda para el historiador del Arte que encuentra en ellos obras que se creían perdidas, otras desconocidas y algunos datos de interés.

Cuando los catálogos de subastas se convirtieron en algo de gran utilidad para el investigador, la revista Archivo Español de Arte, dirigida entonces por Diego Angulo, incluyó en sus páginas un apartado con el título "Mercado de Arte" en el que se recogían las obras de Arte español que aparecían en las principales casas de subastas, tanto de España como del extranjero. La revista Archivo Español de Arte fue fundada en 1925 por Manuel Gómez Moreno y Elías Tormo en el seno del Centro de Estudios Históricos de la Junta de Ampliación de Estudios. Desde entonces se ha seguido publicando con carácter trimestral con la única interrupción de unos números durante la Guerra Civil, fundamentalmente por falta de papel, pero también porque varias de las imprentas madrileñas habían sido incautadas. Su primer título fue Archivo Español de Arte y Arqueología, pero con la fundación de un Instituto de Arte y otro de Arqueología en el nuevo Consejo Superior de Investigaciones Científicas la primitiva revista quedó también dividida en dos revistas una para cada materia.

En principio se publicaban, solamente, artículos inéditos escritos por los investigadores. Pero con el tiempo se fueron añadiendo secciones que ayudaran al investigador en un momento en que la electrónica y las bases de datos quedaban muy lejos en el tiempo. Primero fueron los "Libros recibidos", que ponían al corriente de lo que se iba publicando. Luego la "Bibliografía" que recogía los artículos que aparecían en las más prestigiosas revistas del mundo. $Y$, finalmente, el "Mercado de Arte". El primero se publicó en el 
no 140 que corresponde a octubre de 1962, formaba parte de la Bibliografía y ambas bajo el título genérico de "Aportaciones recientes a la Historia del Arte español". Está sin firmar, pero es posible que lo redactara Carmen Bernis que por entonces hacía la Bibliografía. Desde octubre de 1964 está firmado por Isabel Mateo, que se ocupará de él más de 20 años. Desde 1986 se sucedieron Isabel Mateo-Amelia López-Yarto; Amelia López-Yarto; Amelia López-Yarto-María Luisa Tárraga y, finalmente, María Luisa Tárraga-María Paz Aguiló. Se dejó de publicar, creo que equivocadamente, en 2007 al pensar el Consejo de Redacción de la revista que los medios tecnológicos de los que ahora se disponen hacían innecesaria su publicación.

A diferencia de Murillo, Velázquez, Ribera y más tarde Goya que gozaron de enorme prestigio en vida y que despertaron el interés de los coleccionistas ya en los siglos XVII y XVIII, El Greco pasó totalmente desapercibido. Durante estos siglos y a lo largo del XIX salió una cantidad muy considerable de pintura española hacia el extranjero. Algunas de las colecciones de las que formaron parte se dispersaron al ser subastadas a finales del siglo. En lo que he podido buscar, solo he encontrado documentación de tres grecos vendidos en estos momentos. Uno en la venta de la colección de Luis Felipe y un San Bernardo y la magnífica Asunción de la Virgen del Convento de Santo Domingo el Antiguo de Toledo, comprada en 1827 por el infante don Sebastián Gabriel de Borbón, (hoy en el Art Institute de Chicago). Ya en el siglo XX había muchos grecos en colecciones privadas que fueron fotografiados en las casas de sus dueños por Mariano Moreno, de los que Gaya calcula que el $80 \%$ más o menos fueron vendidos, sobre todo en Estados Unidos (Gaya Nuño, 1958). Según Pérez Sánchez "buena parte del prestigio del Greco se debe a la fijación de ciertas iconografías piadosas cuya vigencia y eficacia se fijan por la frecuencia de sus repeticiones...Pero puso lo mejor de su ingenio y voluntad creadora en los grandes conjuntos de amplio vuelo. El pintor tuvo que valerse en ocasiones de un taller de cuya composición no estamos bien informados" (Pérez Sánchez, 1982). Estos son los cuadros a los que los coleccionistas podían tener mejor acceso.

Y es que a partir de la segunda mitad del siglo XIX y a lo largo del XX, el interés por El Greco fue en aumento, tanto por parte de críticos y coleccionistas, como de los pintores, aunque sus opiniones y teorías no siempre coincidían. Cossío publicó en 1898 un pequeño artículo "La pintura española" en el que comienza a alabar el estilo y la belleza del colorido de El Greco
(Cossío, 1886); en 1902 se organiza una exposición monográfica en el Museo del Prado (Viniegra, 1902) $y$, finalmente, el mismo Cossío publicó la gran monografía en la que por primera vez se hace un estudio científico de su obra, en el que se considera al Greco como un genio de la pintura (Cossío, 1908). Las dos publicaciones y la exposición consiguieron despertar el interés de los coleccionistas, aunque ya a finales del XIX habían salido algunos cuadros, no muchos pero de enorme calidad, como el retrato del cardenal Niño de Guevara y una magnífica Adoración de los Pastores. Es ahora cuando se suceden las ofertas de compra y siguen saliendo obras de primera categoría como los cuadros de la Capilla de San José de Toledo y el extraordinario autorretrato que había pertenecido al pintor Aureliano de Beruete. También salen obras menores como las de iconografía repetida de las cuales, la primera solía ser espléndida y las demás de menor calidad. La procedencia de estas es casi imposible de rastrear, aunque sí es posible seguir, a través de las subastas, cómo pasan de unos coleccionistas a otros.

Para darnos una idea del volumen de pinturas que salieron de España, Gaya Nuño, en su obra anteriormente citada, calcula que un tercio de la producción de El Greco salió de España. Uno de los capítulos se titula "Catálogo del Museo imaginario de la pintura española fuera de España", en el que recoge 291 grecos y 9 de escuela o taller, que estaban tanto en colecciones privadas como en museos. En cuanto a las atribuciones, fechas, firmas y otros datos recoge los publicados por Martín S. Soria, Camón, Palluchini y Mayer fundamentalmente. En años sucesivos y con más conocimientos que los que pudo tener Gaya y los investigadores citados, se han hecho nuevas catalogaciones de la obra de El Greco, que han hecho variar mucho las atribuciones que él utiliza (Álvarez Lopera, 2005 y 2007) 1.

Los primeros años en los que se publicó el "Mercado de Arte", los datos se obtenían de las revistas que se manejaban para elaborar la "Bibliografía" y en ellas aparece el Palais Gallièra (1962-1966) y el Hotel Drouot, de París (1963-1964), Galería Fisched de Lucerna (1966), la Galerie Kröner, Schloss Rimsingen, (Alemania) en mayo de 1980 y, finalmente M. Koedler and co. Inc. de Nueva York, la más antigua galería de Arte en América, pues se inauguró en 1846 y cerró en 2011. Por supuesto, también aparecen en estas revistas noticias sobre las dos grandes casas londinenses Sotheby's y Christie's². Vista la utilidad del "Mercado de Arte" comienzan a efectuarse suscripciones a los catálogos de las más importantes casas extranjeras y se consigue 
que las españolas los envíen gratuitamente ya que suponía una propaganda a nivel mundial, pues la revista cuenta con suscriptores en todo el mundo. Los catálogos editados por las galerías de subastas pasan a ser la principal fuente de datos para elaborar el "Mercado de Arte", por lo que las galerías que figuraban en las revistas no se vuelven a tener en cuenta.

En los años en que se publicó el "Mercado de Arte", son muy raros los números en los que no consta algún cuadro de El Greco en las diversas salas de subastas. Cuando estaba recogiendo el material para este artículo, me iba dando cuenta de los pocos grecos que se vendían en España. Recopilado todo y empezado a valorar, he podido comprobar que, efectivamente, salen muy pocos a subasta o de tan mala calidad que no se recogieron en el "Mercado de Arte". Por ejemplo la casa Sotheby's, que estuvo activa en Madrid muy pocos años, realizaba una o todo lo más dos subastas al año con muy pocas piezas, pero muy escogidas. En estos años saca a subasta varios grecos, auténticos o de escuela o taller, pero de calidad: en junio de 1980 un San Pedro procedente de la colección August L. Berg de San Francisco (California), con un precio de salida de 20.000.000/25.000.000 de pesetas. En junio de 1984 un Retrato de clérigo, obra de escuela por 20.000/30.000 pesetas. San Francisco en meditación procedente de colección particular en abril de 1995 (40.000.000/60.000.000 de pesetas) y una copia de taller del Retrato de fray Hortensio Félix Paravicino en noviembre de 1996 (2.000.000/3.000.000 de pesetas) que ya se había ofertado en la misma casa en mayo de 1980 por una cantidad bastante inferior (600.000/800.000 pesetas).

La italiana Finarte, con sede en Milán, también trabajó pocos años en España, ya que la casa central quebró en 2011. Sacó a subasta un San Francisco recibiendo los estigmas, procedente de colección particular, en noviembre de 1995 por 8.000.000/10.000.000 de pesetas.

Finalmente Arte, Información y Gestión, casa sevillana con correspondencia en Madrid y que ha cerrado definitivamente en noviembre de 2014, sacó a la venta en noviembre de 2003, un San Juan Bautista, por 144.240 euros.

Todos los demás grecos salen en el extranjero. Pero tampoco en todo el mundo. Bien es cierto que no hemos llegado a manejar los catálogos de Oriente pero sí de toda Europa y es en Londres y Nueva York donde Sotheby's y Christie's los venden, especialmente en la capital inglesa.
Por lo general no consta nada más que el nombre del pintor y es la diferencia del precio de salida el que da la pauta para saber la calidad, si es obra del maestro o si es del taller, círculo, discípulo. Como ya se ha dicho más arriba, se sabe muy poco del taller de El Greco, aunque tal y como dice Pérez Sánchez debió de tenerlo pues de otra forma no hubiera sido posible realizar el ingente trabajo que hizo a lo largo de su vida tanto en retablos, con gran número de lienzos, como cuadros de devoción. No sé como se conjuga esto con la calidad de todos los retablos en los que es difícil ver varias manos. Sí es posible, sin embargo, ver la diferente calidad de las series de santos u obras de devoción, cuya iconografía se repite una y otra vez.

En algunas ocasiones consta la procedencia de las obras. Este es el caso de un San Francisco de Asís en meditación obra de El Greco con ayuda del taller vendido en Ch., Nueva York en Octubre de 1998 por $400.000 / 600.000$ \$ y que procede de la ermita de San Blas de Burguillos (Toledo).

Otras veces se pueden seguir las colecciones por las que ha pasado o la colección de la que procedce en ese momento como una Anunciación vendida también en Ch. de Nueva York en enero de 1997, tras pasar por las colecciones de Potestad, Schmidtlapp y Cintas. O un San Pedro vendido en la misma casa y fecha que procede de las colecciones del Marqués de Legarda y H. D. Havemeyer. En Ch. de Londres sale en 1996 por 1.200.000/1.600.000 \$ un San Francisco y el Hermano León en meditación de las colecciones Adanero, Castro Serna, Campo Giro y Albayda. Estos son algunos de los ejemplos que aparecen en los catálogos. Lo más frecuente es que no ponga nada o "procede de colección particular". Por supuesto no consta su ubicación o coleccionista inicial.

En cuanto a los temas predominan las escenas religiosas de iconografía conocida que se repite en varias ocasiones: Anunciación, Última Cena -este tema suele aparecer en obras catalogadas como de época veneciana-, El Paño de la Verónica, Sagrada Familia, Cristo abrazado a la cruz, La Virgen, El Expolio, La Oración en el huerto, La Magdalena penitente y algunos retratos. Por supuesto no faltan los santos a veces emparejados. Pero hay una total preferencia por San Francisco de Asís en todas las escenas conocidas, fundamentalmente meditando con o sin una calavera en las manos, en oración con el hermano León y recibiendo los estigmas. En ocasiones se citan escenas religiosas poco comunes como El quinto signo del Apocalipsis, que es un dibujo (S. Londres, 1964, 160 f). Llama la atención la presencia en las subastas de dos dibu- 
jos, además del ya citado, con los Santos Juanes que salieron juntos en 1963 en S. de Londres por $240 \mathrm{f}$.

Aparecen también escenas populares poco frecuentes en la pintura española del siglo XVI y de las que no quedó ninguna en España hasta fechas recientes. Son dos temas fundamentalmente: Una fábula, adquirida en 1983 por el Museo del Prado con fondos del Legado Villaescusa. Se trata de un título convencional que aparece en un inventario de su hijo y que podía estar relacionada con la literatura clásica. Según la ficha redactada por José Manuel Pita Andrade para la Enciclopedia on line del Museo, la figura del centro puede ser una mujer que oculta su pelo con una toca. Sopla un tizón para encender una candela que tiene en la mano derecha. A los lados, un hombre riéndose y un mono. Pero en otra ficha de la galería, también on line, que recoge datos de una publicación de L. Ruiz, dice que se trata de un muchacho ${ }^{3}$. Es un tema que, con variantes iconográficas, aparece varias veces en los catálogos de ventas y con diversos títulos: Niño encendiendo una vela (Ch. Nueva York, 1998. Sin precio de salida), Fábula, obra de taller (Ch. Nueva York 1988, 30.000-40.000 \$), Hombre mujer y mono, (S. Londres, 1962, $5.000 \mathrm{f})$.

Otro tema que aparece es el titulado Grupo Familiar - La familia. Indudablemente es una escena íntima por lo que se supone que puede ser la propia familia del pintor o la de su hijo. Salió dos veces en Ch. de Londres. La primera en 1966 (82.300 \$) y la segunda en 1976 (13.000 f). Esta última fue adquirida para el Museo de la Academia de Bellas Artes de San Fernando en los primeros años 80 del siglo XX con los fondos del legado Guitarte. En el catálogo figura como Familia del Greco y consta como obra de taller. Algunos autores opinan que es obra de Jorge Manuel y que se trata de su propia familia.

Finalmente un Paisaje de Toledo salió en Ch. Nueva York en 1986 por 8.000-12.000 \$. Una Vista del Monte Sinaí en S. Londres en 1988 por 500.000-700.000 libras. Y con tema distinto Tres cabezas de ángeles (Galerie Kröner, 1980, del que desconocemos el precio de salida), aunque es posible que se trate de una parte recortada de un cuadro de mayor tamaño.

Es muy difícil hacer una valoración de los cambios de los precios de salida de los cuadros de El Greco a lo largo de los años. Y no solo porque varias figuran sin precio de salida o se omitió al tomar nota así como la inflación de las monedas y la desaparción de algunas ante el euro, sino también porque en las salas de subastas suelen figurar sin distinguir la atribución al
Greco o a su círculo, que aparece tímidamente en los años 70 y es más frecuente en los 80 y 90, los años en que se vendieron más cuadros del pintor. Otra cosa que llama la atención es la variedad de apartados en los que dividen las obras no auténticas: de escuela, círculo, taller, estudio, copia o seguidor, aunque da la sensación de que no distinguen muy bien uno de otro y generalizan para distinguir los originales.

Lo más frecuente es que el autor figure solo con el nombre, sin el añadido de taller etc., pero con diferencias de precio muy grandes. No incluyo en este acercamiento a la valoración de El Greco, los tres dibujos. Empezando por la década de los 60, que es de la que tenemos menos noticias, pero que a pesar de ello conocemos bastantes ventas, la más barata es una Virgen leyendo (Ch. Londres, 1963) por $100 \$(42$ '5 $x$ 23'15 cm.). El más caro es un Cristo en la cruz con una vista de Toledo (Ch. Londres, 1966), por 117. 600 $\$(110 \times 60 \mathrm{~cm})$. Son tres años los que han pasado, el dolar no cambió de valor y el tamaño no pudo influir en una diferencia tan grande del precio. Debió de ser la calidad valorada por los tasadores, aunque en el catálogo figuren ambos como obra de El Greco. Entre ambas cifras encontramos Un hombre, una mujer y un mono, citado más arriba, (S. Londres, 1962) por 5.000 $f$, o el San Juan Bautista (Ch. Londres, 1966), por 57.200 y La familia (Ch. Londres, 1966), por 83.300 $\$$. Los demás oscilan entre los 15.000 y los 27.500 .

En la década de los 70 no salen grandes obras y por lo tanto no cambian mucho las valoraciones que oscilan entre las 100 y las $50.000 \mathrm{f}$, sin que ninguna llegue a las más altas del periodo anterior. La que en esos años alcanza una mayor valoración, es un San Pedro procedente de la colección August L. Berg (S. Madrid, 1980) que salió por 20.000.000/25.000.000 de pesetas.

En los años 80 se venden muchos grecos, especialmente en Londres. Los precios han subido. No aparecen esas obras que costaban entre 100 y $200 \$$. Salen a partir de $6.000 \$$ o $10.000 \mathrm{f}$, pero la mayoría son a partir de las 60.000-80.000 £. También hay alguna que sobresale. Un San Juan Evangelista, procedente de la colección de Mr. and Mrs. Kay Kimbell (S. Nueva York, 1987) que salió por 300.000-400.000 \$. Una Vista del monte Sinaí (S. Londres, 1988, procedente de colección privada de Viena) salió por 500.000-800.000 £.

En la década de los 90 salen muchos menos grecos tasados como auténticos y bastantes más de escuela, taller etc. Pero salvo algún caso que sale por $6.000 £$ o $15.000 \$$, los precios se disparan. En Madrid, todos los cuadros salen, por lo general, con precios inferiores al 
resto de Europa. Un San Francisco en meditación (S. Madrid, 1965) fue tasado en 40.000.000/80.000.000 de pesetas. Y San Francisco recibiendo los estigmas (Finarte, Madrid, 1995) en 8.000.000/10.000.000 de pesetas. En Ch. de Nueva York salieron tres: Entierro de Cristo (1995) es valorado en 250.000-350.000\$. Un Expolio (1996) en 250.000-300.000 \$. San Francisco de Asís en meditacion (1998), procedente de la ermita de San Blas de Burguillos (Toledo) y vendido a principios del XX, en 400.000-600.000\$. Por su parte Ch de Londres (1996) sacó un San Francisco y el hermano León en meditación por 700.000-1.000.000 f.

En cuanto a los años 2000/2007 sale a la venta un número bastante menor de grecos y aumenta el de taller, seguidor etc. Pero tasados con precios altos. Donde sale un número mayor es en Ch. de Londres. Una Huida a Egipto (2001) por 1.200.000-1.800.000 f; Cristo con la cruz a cuestas (2001), 100.000-150.000 f; San Francisco meditando (2004) por 1.100.000$1.500 .000 \mathrm{f}$. Finalmente a pesar de que figura como obra de El Greco con intervención de taller, un Expolio (2006) sale por 590.000-870.000 f. También en Londres pero en S. salió un Cristo crucificado, (2000) por $600.000-800.000 \mathrm{f}$.

En Nueva York salen dos: uno en Ch. San Pablo (2000) por 1.500.000- 2.500.000 \$. Y dos en S. Magdalena penitente (2001) por 600.000-800.000 \$.

En España, la Sala Arte, vendió un San Juan Bautista (2003) con salida en 144.240 euros.

En cuanto a los catalogados como obra de escuela, círculo, taller, estudio, seguidor o copia, no hay ninguno en la década de los 60, muy pocos en las de los 70 y 80 y van creciendo a lo largo de las demás. Como dije más arriba es difícil saber con qué criterio lo hacían y si de verdad distinguían entre las seis categorías. Los precios son similares en todos ellos. Complica las cosas el que muchos no tienen precio de salida.

En los 60 y a partir del 2000 no hay ninguno de "escuela". En la década que más hay es en la de los 80 . Los precios son muy variados, pero más altos en los 90. Van desde el Retrato de caballero (Ch. Londres, 1983) por 2.000-3.000 $\mathrm{f}$, hasta un San Francisco (Ch. Nueva York, 1990), por 30.000-40.000 \$, el mismo precio de salida que el de una Anunciación (Ch. Nueva York, 1997).

Catalogados como de "círculo" salen cuatro, todos en los 90 y en Ch. de Nueva York por lo que quizá fueron tasados por el mismo especialista que utilizó este término en vez de los otros citados. Pero no hay tanta oscilación de precios: Dos de ellos salen en Ch. Nueva York en 1995 y con el mismo precio de salida:15.000-20.000 \$: San Francisco de Asis y fray Leone y San Pablo. Un poco más caro es un San Francisco recibiendo los estigmas (Ch. Nueva York, 1992) que sale por 25.000-35.000\$, el mismo precio de salida que una Anunciación de Ch. Nueva York en 1993. Sube mucho el precio un cuadro con Las Lagrimas de San Pedro (Ch. Londres, 1997) que sale por 60.000-80.000 f.

Los de "taller" no son muchos pero, en conjunto, son algo más caros. Por orden cronólogico, el primero que sale es el Retrato de fray Hortensio Paravicino (S. Madrid, 1980) por $600.000-800.000$ pesetas. Este cuadro vuelve a salir en la misma sala en 1996 por 2.000.0003.000.000 de pesetas. Una Fábula (Ch. Nueva York, 1988) por 30.000-40.000 \$. San Lucas (S. Nueva York, 1997), 35.000-55.000 \$. Y, finalmente, San Francisco (Ch. Nueva York, 1999), 25.000-35.000 \$. Solo un San Francisco y el Hermano y el hermano León (Ch. Londres, (2004) alcanzó las 120.000-170.000 f.

De "estudio" solo salió El Apostol Santiago (Ch. Londres, 1980) por $3.500 \mathrm{f}$.

También sale solo uno como "copia". Se trata de un Expolio (S. de Nueva York, 1988) por 15.000-20.000\$.

A partir de los años 90 salen bastantes de "seguidores" con unos precios que no varían mucho unos de otros. No sale sin embargo prácticamente ninguno con otra atribución, sobre todo en el periodo $2.000 / 2007$. El precio más corriente es entre 8.000 y las $15.000 \mathrm{f}$ o \$. Por poner unos ejemplos, una Virgen vendida en Ch. Londres en 1990 sale por 8.000-12.000 $\mathrm{f}$; San Francisco en meditación (S. Londres, 1996) 11.000-15.000 f. En Nueva York una Crucufixión, (S. 2003), 10.000-15.000 \$. San Francisco y el hermano León meditando (Ch. 2006), por 15.000-20.000\$. Y en esta misma casa y año una Magdalena penitente por 20.000-30.000\$.

En España sale en Finarte de Madrid (1995), un San Francisco recibiendo los estigmas por 8.000.00010.000.000 de pesetas.

Al principio decía que las publicaciones y la exposición de El Greco de principios del siglo XX alertaron a los coleccionistas europeos de la calidad de este pintor. No me atrevería a asegurar, por falta de datos, que las exposiciones que tuvieron lugar en 1982 (El Greco de Toledo en el Museo del Prado de Madrid y El Toledo del Greco en el Museo de Santa Cruz de Toledo) tuvieron algo que ver con el mayor índice de salida al mercado de arte de cuadros de este pintor. Tampo- 
co puedo vaticinar qué repercusión puedan tener en el futuro de las ventas de sus obras las exposiciones que están teniendo lugar a lo largo de este año 2014 con motivo del centenario de la muerte del pintor y que han despertando tanto interés. Pero creo que la conclusión que se puede sacar de este breve estudio es que la pintura de El Greco cada vez despierta más interés y están saliendo a subastas algunas piezas de muy buena calidad.

\section{NOTAS}

[1] Hay que citar de manera muy especia la monumental obra de Álvarez Lopera, cuya prematura muerte hizo que quedara inconclusa.

\section{BIBLIOGRAFÍA}

Álvarez Lopera, J. (2005). El Greco. Estudio y catálogo (volumen I. Fuentes y bibliografía). Madrid: Fundación de Apoyo a la Historia del Arte Hispánico.

Álvarez Lopera, J. (2007). El Greco. Estudio y catálogo (volumen II. Catálogo de obras originales: Creta, Italia. Retablos y grandes encargos en España). Madrid: Fundación de Apoyo a la Historia del Arte Hispánico.

Bailén Vega, J. P. (2007). Arte español en las grandes casas de subastas. En Ramos Sáinz, M. L. e Iglesias Gil, J. M. (eds.). Actas de los XVII Cursos monográficos sobre Patrimonio Histórico (Reinosa, julio 2006). Santander: Ayuntamiento de Reinosa, pp. 213-224.

Cossío, M. B. (1886). La pintura española. En Gillman, F. Enciclopedia popular ilus-
[2] No entro a evaluar las atribuciones que son las que aparecen en los catálogos.

trada de ciencias y artes (vol. IV). Madrid: Gras y compañía, pp. 740-804.

Cossío, M. B. (1908). El Greco. Madrid: Victoriano Suárez.

Gaya Nuño, J. A. (1958). La pintura española fuera de España. Madrid: Espasa Calpe.

Pérez Sánchez, A. (1982). Las series dispersas del Greco. En VV. AA. El Greco de Toledo. Madrid: Ministerio de CulturaFundación Banco Urquijo, pp. 149-176.

Ruiz López, J. I. (2007). Introducción al Mercado del Arte en España. En Ramos Sáinz, M. L. e Iglesias Gil, J. M. (eds.). Actas de los XVII Cursos monográficos sobre Patrimonio Histórico (Reinosa, julio 2006). Santander: Ayuntamiento de Reinosa, pp. 117-127.
[3] Véase en la Bibliografía la referencia electrónica.
Vico Belmonte, A. (2008). El mercado de las subastas en el arte y el coleccionismo: desde sus orígenes a la actualidad. En Prado Román, C. y Vico Belmonte, A. (coords.). La inversión en Bienes de Colección. Madrid: Universidad Rey Juan Carlos, pp. 1-23.

Viniegra, S. (1902). Catálogo ilustrado de la exposición de las obras de Domenico Theotocopuli llamado el Greco. Madrid: J. Lacoste.

VV. AA. Enciclopedia del Museo del Prado [en línea]. Recuperado de https://www. museodelprado.es/enciclopedia/enciclopedia-on-line/voz/fabula-el-greco/.

VV. AA. Galería del Museo del Prado. [en línea]. Recuperado de https://www.museodelprado.es/coleccion/galeria-online/galeria-on-line/obra/fabula/. 